\title{
Radiosurgery for benign tumors of the spine using the Synergy S with cone-beam computed tomography image guidance
}

\author{
Clinical article
}

\author{
Peter C. Gerszten, M.D., M.P.H., ${ }^{1,2}$ Stephanie Chen, B.S., ${ }^{3}$ Mubina Quader, Ph.D., ${ }^{2}$ \\ Yuanguang Xu, Ph.D., ${ }^{2}$ Josef Novotny JR., Ph.D., ${ }^{2,4,5}$ and John C. Flickinger, M.D. ${ }^{1,2}$ \\ Departments of ${ }^{1}$ Neurological Surgery and ${ }^{2}$ Radiation Oncology, University of Pittsburgh Medical Center; \\ ${ }^{3}$ University of Pittsburgh School of Medicine, Pittsburgh, Pennsylvania; ${ }^{4}$ Department of Medical Physics, Na \\ Homolce Hospital, Prague; and ${ }^{5}$ Institute of Biophysics and Informatics, First Faculty of Medicine, Charles \\ University in Prague, Czech Republic
}

\begin{abstract}
Object. There is a growing body of evidence to support the safe and effective use of spine radiosurgery. However, there is much less experience regarding the use of radiosurgery for the treatment of benign as opposed to malignant spine tumors. This study represents an evaluation of, and reporting on, the technical aspects of using a dedicated radiosurgery system for the treatment of benign spine tumors.

Methods. Forty-five consecutive benign spine tumors were treated using the Elekta Synergy S 6-MV linear accelerator with a beam modulator and cone-beam computed tomography (CBCT) image guidance technology for target localization. The study cohort included 16 men and 29 women, ranging in age from 23 to 88 years (mean age 52 years). There were 14 cervical, 12 thoracic, 14 lumbar, and 5 sacral tumors. Forty-one lesions (91\%) were intradural. The most common histological types of tumor were schwannoma, neurofibroma, and meningioma. Indications for radiosurgery included primary treatment in 24 cases $(53 \%)$ and treatment of recurrent or residual tumor after open resection in 21 cases $(47 \%)$.

Results. No subacute or long-term spinal cord or cauda equina toxicity occurred during the follow-up period (median 32 months). The mean maximum dose received by the gross tumor volume (GTV) was 16 Gy (range 12-24 Gy) delivered in a single fraction in 39 cases. The mean lowest dose received to the GTV was 12 Gy (range 8-16 Gy). The GTV ranged from 0.37 to $94.5 \mathrm{~cm}^{3}$ (mean $13.7 \mathrm{~cm}^{3}$, median $5.9 \mathrm{~cm}^{3}$ ). In the majority of cases, a planning target volume expansion of $2 \mathrm{~mm}$ was employed (38 cases; $84 \%$ ). The mean maximum point dose delivered to the spinal cord was $8.7 \mathrm{~Gy}$ (range 4-11.5 Gy); the mean volume of the spinal cord that received greater than $8 \mathrm{~Gy}$ was $0.9 \mathrm{~cm}^{3}$ (range $0.0-5.1 \mathrm{~cm}^{3}$ ); and the mean dose delivered to $0.1 \mathrm{~cm}^{3}$ of the spinal cord was $7.5 \mathrm{~Gy}$ (range 3-10.5 Gy). The mean maximum point dose delivered to the cauda equina was $10 \mathrm{~Gy}$ (range $0-13 \mathrm{~Gy}$ ); the mean volume of the cauda equina that received greater than $8 \mathrm{~Gy}$ was $1.45 \mathrm{~cm}^{3}$ (range $\left.0.0-10.6 \mathrm{~cm}^{3}\right)$; and the mean dose delivered to $0.1 \mathrm{~cm}^{3}$ of the cauda equina was 8 Gy (range $0.5-11 \mathrm{~Gy}$ ).

Conclusions. In this study the authors describe the contouring and prescribed dose techniques used in the treatment planning and delivery of radiosurgery for benign neoplasms of the spine using CBCT image guidance. This technique may serve as an important reference for the performance of radiosurgery when one believes it is clinically indicated as a treatment modality for a benign spine tumor that is associated with both a high safety profile and a strong positive clinical outcome.

(http://thejns.org/doi/abs/10.3171/2012.8.GKS12981)
\end{abstract}

\section{KEY Words • cone-beam computed tomography • spine radiation treatment $\bullet$ spine tumor $\bullet$ stereotactic radiosurgery $\bullet$ meningioma • neurofibroma • schwannoma}

$\mathrm{S}$ TEREOTACTIC radiosurgery for the treatment of a variety of benign intracranial lesions has become widely accepted; it has excellent long-term outcomes and is associated with minimal toxicity. ${ }^{17,34,37,51,59}$ Radiation therapy has been used for the treatment of numerous benign diseases for decades. ${ }^{29,31,36,54,57}$ Benign tumors of the spine represent a wide variety of histologi-

Abbreviations used in this paper: $\mathrm{CBCT}=$ cone-beam computed tomography; GTV = gross tumor volume; OAR = organ at risk; PTV $=$ planning target volume. cal types of lesions that occur within the intradural space as well as in epidural, paraspinal, and vertebral body locations. The primary treatment option for many benign spinal neoplasms is open resection. The safety and effectiveness of such surgery has been clearly documented. ${ }^{8,32-37}$ The majority of spinal meningiomas, schwannomas, and neurofibromas are noninfiltrative and can be completely and safely resected using microsurgical techniques. ${ }^{2,38,39,43}$ When complete tumor removal is achieved, recurrence is unlikely. $7,32,35,41$

In certain circumstances, however, some patients are 
less than ideal candidates for standard open resection because of age, medical comorbidities, recurrent nature of the tumor, or anatomical location of the lesion. ${ }^{16}$ Tumors that have recurred after open resection may make safe resection challenging or impossible. Multiple benign spinal tumors, which are commonly found in familial neurocutaneous disorders, may be a pattern of spinal disease better suited for a less invasive radiosurgical option. It is in such clinical circumstances that radiosurgery may serve as an important treatment option for these patients.

The recent development of frameless image-guided radiosurgery allows for the ability to treat benign tumors throughout the body. ${ }^{1,16,18,21,50}$ There is now a substantial body of literature that supports the use of extracranial radiosurgery for the treatment of a variety of malignant spinal tumors. . $^{3,8-10,12,14,15,22,23,26,28,40,41,44,46,47,49,50,58,61,62}$ Nevertheless, there is much less experience regarding the use of radiosurgery for the treatment of benign tumors of the spine.

Cone-beam computed tomography image guidance technology now has been adapted for radiosurgical setup with delivery by a variety of radiosurgery delivery systems..$^{20,27,53}$ The clinical experience and current trends at our center for radiosurgery in the treatment of benign tumors of the spine has recently been reported ${ }^{21}$ Given the gradual widespread adoption of radiosurgery as part of the management of benign spine tumors ${ }^{42}$ this study was undertaken to carefully evaluate and report on the technical aspects of radiosurgery for benign tumors of the spine using a CBCT image guidance technique.

\section{Methods}

Forty-five consecutive benign spine tumors underwent radiosurgery treatment and were evaluated in an institutional review board-approved investigation. Radiosurgery was offered to patients for whom microsurgical resection was believed to be contraindicated or in cases of strong patient preference. All cases had well-circumscribed lesions, no evidence of spinal instability, and generally minimal compromise of spinal cord function. All of the patients were carefully followed up by a dedicated research nurse using Gd-enhanced MRI at 3, 6, and 12 months and yearly thereafter. Neurological examination and the occurrence of any toxicity were evaluated in person at each follow-up imagining time point or by telephone if necessary.

All lesions were treated using the Elekta Synergy S 6-MV linear accelerator with a beam modulator and CBCT image guidance combined with a HexaPOD couch that allows correction of patient positioning in 3 translational and 3 rotational directions. In a plane orthogonal to the linear accelerator, the CBCT image guidance system is mounted on the gantry. Our technique for utilizing CBCT for radiosurgical image guidance has been described elsewhere. ${ }^{19,20}$

\section{Summary of Study Cohort}

The study cohort included 16 men and 29 women, ages 23 to 88 (mean age 52 years). Table 1 lists the characteristics of the treatment group. Lesion location included 14 cervical, 12 thoracic, 14 lumbar, and 5 sacral tumors. The Karnofsky Performance Scale scores for the cohort ranged from $70 \%$ to $90 \%$ (mean $88 \%$ ). The most common histological types of tumor were schwannoma (16 cases), neurofibroma (14 cases), and meningioma (10 cases). The remaining histological types included ganglioglioma, hemangioma, aneurysmal bone cyst, and giant cell tumor. Nine patients had previously diagnosed neurofibromatosis. In 41 cases $(91 \%)$ the tumors were intradural. Radiosurgery was used as the primary treatment modality in 24 cases (53\%) and for tumor recurrence after prior open resection in 21 cases $(47 \%)$. Nineteen patients (42\%) reported a significant component of pain before radiosurgery. Figure 1 demonstrates a representative case.

Six patients (13\%) had undergone surgical stabilization at the time of open resection and therefore spinal instrumentation was present at the time of the radiosurgical treatment. All patients were believed to have a stable spine at the time of radiosurgery. Two lesions had been treated with prior radiotherapy at the index location. Magnetic resonance imaging (or CT myelography when the patient could not undergo MRI) was fused with the planning CT scan for contouring purposes in all cases if possible. The prescribed dosage and fractionation were based on tumor size, volume, and location; the degree of potential spinal cord exposure; and history of previous irradiation. The radiosurgery procedure was successfully completed in all patients.

\section{Data Collection}

The data collected for each case were entered into a database developed by the Elekta Spine Radiosurgery Research Consortium. This is an international research consortium consisting of 6 institutions, all of which have a research and clinical focus on image-guided high-precision radiotherapy with a particular focus on spine radiosurgery. The data set has a particular focus on contouring and prescription techniques as well as toxicity documentation.

\section{Results}

The patients were immobilized with the aid of a BodyFix (total body bag, Medical Intelligence) when treatment sites were below T-6; otherwise, a head and shoulder mask with an S-board (CIVCO) was used. The Pinnacle treatment planning system (version 8.0, Philips) and a $1.5-\mathrm{mm}$ CT slice thickness were used to plan all spine radiosurgery treatments. Fourteen patients were immobilized using a mask, and 31 patients were immobilized using the BodyFix.

\section{Imaging Evaluation}

The relationship of the tumor to the spinal cord or cauda equina was graded using the scoring system described by Bilsky et al. ${ }^{7}$ for each case based on MRI. The distribution of case by grade was as follows: Grade 0,7 cases; Grade 1a, 2 cases; Grade 1b, 3 cases; Grade 1c, 1 case; Grade 2, 25 cases; and Grade 3, 7 cases. The degree of circumferential enclosure of the spinal cord or cauda equina was recorded for each case, and then patients were divided into the following groups: $0^{\circ}-90^{\circ}, 18$ cases; $90^{\circ}-180^{\circ}, 18$ cases; $180^{\circ}-270^{\circ}, 6$ cases; and $270^{\circ}-360^{\circ}, 3$ 
TABLE 1: Characteristics in 45 patients who underwent radiosurgery for benign spine tumors

\begin{tabular}{lc}
\hline \multicolumn{1}{c}{ Characteristic } & Value \\
\hline $\begin{array}{l}\text { age in yrs } \\
\text { mean }\end{array}$ & 52 \\
range & $23-88$ \\
sex-no. of patients (\%) & \\
female & $16(36)$ \\
male & $29(64)$ \\
intradural location-no. of lesions (\%) & $41(91)$ \\
lesion location-no. of lesions & \\
$\quad$ cervical & 14 \\
thoracic & 12 \\
lumbar & 14 \\
sacral & 5 \\
mean GTV in cm ${ }^{3}$ (range) & $13.7(0.4-94.5)$ \\
mean prescribed max dose to GTV in Gy (range) & $16(12-24)$ \\
histological type-no. of lesions & \\
meningioma & 10 \\
schwannoma & 16 \\
neurofibroma & 14 \\
other & \\
primary indication for treatment-no. of patients (\%) & \\
primary treatment modality & $24(53)$ \\
recurrence after open resection & $21(47)$ \\
\hline
\end{tabular}

cases. A significant degree of paraspinal involvement of the tumor was present in 13 cases $(29 \%)$. No evidence of tumor growth was seen on serial images within the GTV during the follow-up period (median 32 months, range 3-55 months).

\section{Contouring and Dosimetric Evaluation}

An MRI fusion technique was used for target delineation in 42 cases (93\%). The target volume concept employed in all cases was the GTV, as seen on enhanced imaging. A clinical target volume was not used for the benign tumors. In 10 cases, the lesions spanned more than a single vertebra. Our experience has shown that accurate contouring of benign spine tumors is nearly impossible without the use of MRI fusion. High-resolution-sequence MRI often improves resolution degraded by instrumentation. In cases of instrumentation, we have attempted to resolve questions of tumor definition by performing CT myelography. Titanium implants are preferred over stainless steel to decrease the imaging artifact. In some cases in which radiosurgery is already anticipated prior to open surgery, such as in cases involving large "dumbbell" foraminal tumors, spinal instrumentation is only placed on the contralateral side of the tumor to allow for maximum tumor definition for radiosurgery.

The mean maximum radiation dose received by the GTV was 16 Gy (range 12-24 Gy) delivered in a single fraction in 39 cases. In 6 cases in which the tumor was found to be intimately associated with the spinal cord,

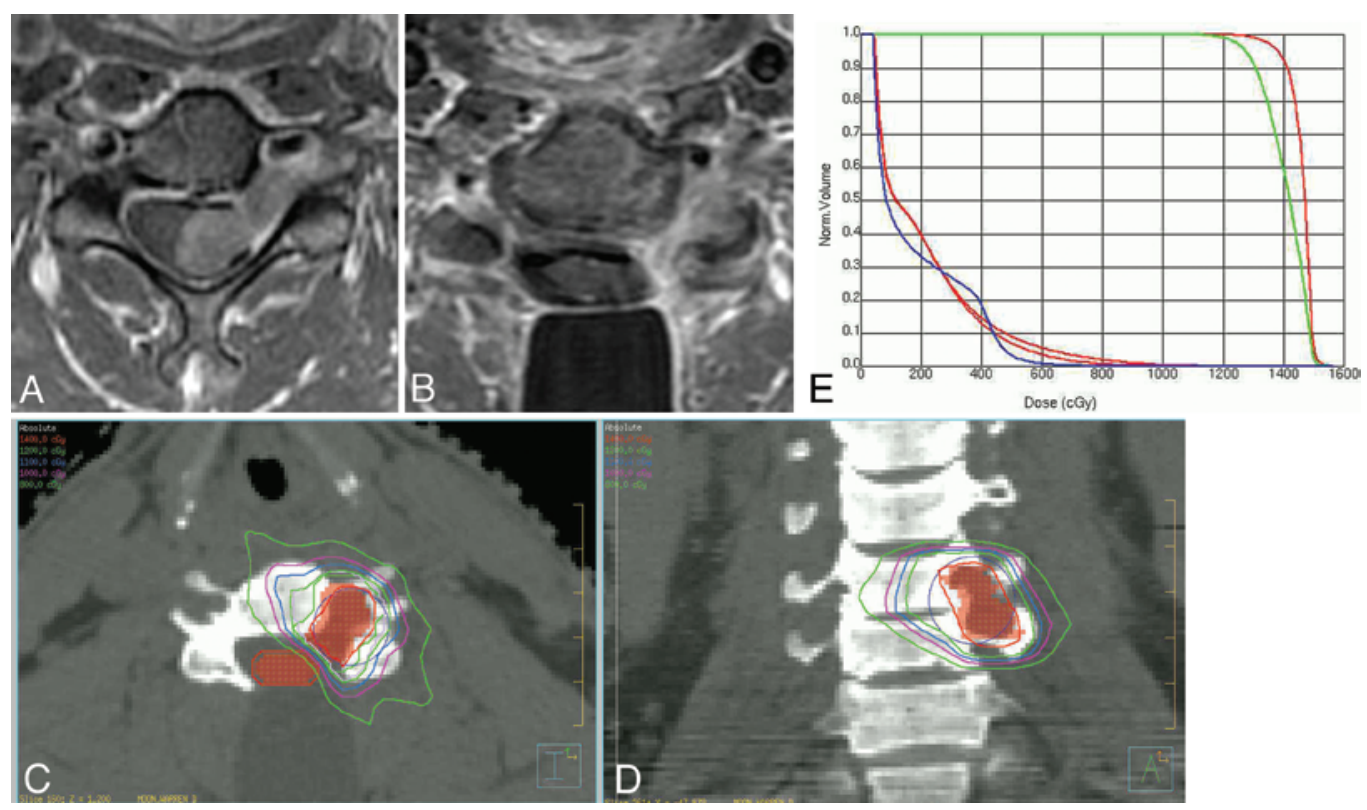

FIG. 1. Representative case of a 49-year-old man who presented with a symptomatic left C5-6 neurofibroma associated with spinal cord compression. A: Preoperative axial T1-weighted Gd-enhanced MR image demonstrating the tumor. The patient underwent surgical decompression and partial resection of the tumor. B: Postoperative axial T1-weighted Gd-enhanced MR image demonstrating residual tumor. The patient had residual weakness and significant radicular pain and was referred for radiosurgery. $\quad$ C and D: Axial (C) and coronal (D) CT scans showing the isodose lines of the treatment plan. The GTV was prescribed at $14 \mathrm{~Gy}$, which was delivered in a single fraction with a 2-mm PTV expansion of $12 \mathrm{~Gy}$. The maximum dose delivered to the spinal cord was $10 \mathrm{~Gy}$ with a 1-mm safety expansion that received a maximum dose of $9 \mathrm{~Gy}$. E: Dose-volume histogram of the radiosurgery treatment plan demonstrating $90 \%$ coverage of the GTV and $99 \%$ coverage of the PTV. The patient reported significant improvement in his symptoms within 1 month. 
with distortion of the spinal cord itself, the prescribed dose to the GTV was delivered in 3 fractions. The mean lowest dose received by the GTV was 12 Gy (range 8-16 Gy). The GTV ranged from 0.37 to $94.5 \mathrm{~cm}^{3}$ (mean 13.7 $\mathrm{cm}^{3}$, median $5.9 \mathrm{~cm}^{3}$ ).

A PTV expansion was used to account for targeting inaccuracies. In the majority of cases, a PTV expansion of $2 \mathrm{~mm}$ was employed (38 cases; $84 \%$ ). The remaining PTV expansion ranged from 0 to $3 \mathrm{~mm}$. As a rule the PTV prescribed dose was 2 Gy less than the prescribed dose to the GTV. The mean number of beams used to deliver radiosurgical treatment was 10 (median 9 beams, range $7-14$ beams).

\section{Clinical Evaluation and Toxicity}

No subacute or long-term spinal cord or cauda equina toxicity occurred during the follow-up period (median 32 months, range 3-55 months). Furthermore, no acute radiation-induced dermatitis nor acute dysphagia was encountered. A single patient with a C-2 lesion reported the sensation of neck swelling with questionable dysphagia 1 month after treatment; this completely resolved. No acute fracture secondary to radiation-induced osteopenia was encountered during the follow-up period. There were no deaths in this series.

Nineteen patients $(42 \%)$ reported a significant component of pain before radiosurgery. Fifteen of these patients reported a significant improvement or complete resolution of pain at the last follow-up. Fifteen patients had a neurological deficit on examination before radiosurgery (motor and sensory in 5 patients and sensory alone in 10 patients). Four motor deficits remained stable as of the last follow-up, and 1 motor deficit worsened in a patient with neurofibromatosis Type 1 . Ten sensory deficits improved according to patient reports as of the last followup, and 1 sensory deficit worsened again in a patient with neurofibromatosis Type 1 .

The planning spinal cord OAR was defined as the spinal cord itself based on MRI or CT myelography in all cases. The planning cauda equina OAR was defined as the nerve roots themselves based on MRI, especially in cases of intradural or foraminal tumors. A 1-mm expansion of the spinal cord OAR was used for lesions at the level of the spinal cord, with a maximum tolerance dose of $1 \mathrm{~Gy}$ greater than the spinal cord OAR.

The mean maximum point dose to the spinal cord in this series for the 26 tumors located at the level of the spinal cord was 8.7 Gy (range 4-11.5 Gy). The mean volume of the spinal cord that received greater than $8 \mathrm{~Gy}$ was $0.9 \mathrm{~cm}^{3}$ (range $0.0-5.1 \mathrm{~cm}^{3}$ ). The mean dose to 0.1 $\mathrm{cm}^{3}$ of the spinal cord in these 26 cases was $7.5 \mathrm{~Gy}$ (range $3-10.5 \mathrm{~Gy})$.

The mean maximum point dose to the cauda equina for the 18 lesions located at the level of the cauda equina was $10 \mathrm{~Gy}$ (range $0-13 \mathrm{~Gy}$ ). The mean volume of the cauda equina that received greater than 8 Gy was $1.45 \mathrm{~cm}^{3}$ (range $0.0-10.6 \mathrm{~cm}^{3}$ ). The mean dose to $0.1 \mathrm{~cm}^{3}$ of the cauda equina was 8 Gy (range $0.5-11 \mathrm{~Gy}$ ).

\section{Discussion}

Radiosurgery represents a great advance in the treat- ment of both benign and malignant spine tumors. Radiosurgery has been documented to be an effective treatment modality for a variety of malignant tumors of the spine and spinal cord. . $^{3,8-10,12,14,15,22,23,26,28,40,41,44,46,47,49,50,58,62}$ Given their pathological similarities, there is no reason why benign spinal tumors would not be equally as responsive to radiosurgery as their intracranial counterparts. ${ }^{10,11,16,32-35,45}$ Multiple publications have now documented the safety as well as the long-term efficacy of radiosurgery for benign spinal tumors, including a 10-year follow-up experience. ${ }^{4,16,21}$

There are significant differences between benign and malignant tumors of the spine that have affected the adoption of radiosurgery as a treatment modality for these benign lesions. The primary treatment option for most benign spinal neoplasms is microsurgical removal without adjuvant radiotherapy. The safety and effectiveness of such surgery has been clearly documented. . $^{13,16,24,30,43,55,56}$ In certain circumstances, however, some patients are less than ideal candidates for standard open resection because of age, medical comorbidities, the recurrent nature of the tumor, or the presence of multiple lesions occurring in the setting of a phakomatosis. ${ }^{16}$ It is in such clinical circumstances that radiosurgery may serve as an important treatment option for these patients.

Because the life expectancy of many patients with metastatic spine disease is rather limited and because radiation injury to normal structures such as the spinal cord can take years to manifest, ${ }^{16}$ there is substantial controversy regarding radiosurgery for the management of benign tumors of the spine. These benign tumors most frequently occur in patients with normal life expectancies. These lesions often are also intradural, with a close or sometimes contiguous anatomical relationship to the spinal cord or cauda equina. For this reason, the long-term consequences of neural toxicity secondary to radiosurgery perhaps are of even greater importance to patients with benign tumors than to those with metastatic spine disease. Furthermore, benign spine tumors have their own unique presentation, relationship to the spinal cord, and radiobiological response to radiosurgery, all of which represent unique challenges to the safe and effective application of radiosurgical ablation. ${ }^{16}$

Regardless of the delivery system used, in all cases the radiosurgical treatment plan must tightly conform the prescribed dose to the tumor target, while featuring deep dose gradients at the lesion's edge and the immediately surrounding normal tissue..$^{60} \mathrm{In}$ the current paper we describe the technique that we have used for contouring benign tumors based on careful target delineation using MR fusion such that the GTV is defined as the edge of the visualized tumor. A PTV expansion of $2 \mathrm{~mm}$ is usually used for all tumors of the foramen at the level of the spinal cord as well as for tumors of the cauda equina and those in paraspinal locations. However, in instances in which the tumor is intimately associated with the spinal cord itself, no such PTV expansion is used. For cases in which the spinal cord itself is deformed by a tumor within the spinal canal, radiosurgical treatment is delivered in three separate sessions.

For spine radiosurgery, the spinal cord and cauda equina are the OARs that most frequently limit the pre- 
scribed target dose.$^{25}$ Considerable attention has been given to attempted determinations of the radiation tolerance of the human and animal spinal cord and cauda equina to stereotactic body radiotherapy. ${ }^{5,6,48,50,52}$ In the present study we carefully report on the maximum point dose, mean volume receiving greater than $8 \mathrm{~Gy}$, and mean dose to $0.1 \mathrm{~cm}^{3}$ for both the spinal cord as well as the cauda equina. Such doses to these neural structures were associated with an absence of radiation-induced toxicity.

\section{Conclusions}

Radiosurgery is a safe and clinically effective treatment alternative for some benign spinal neoplasms. Such lesions include those in which there is relatively little direct compression on the spinal cord, allowing for the safe delivery of a therapeutic dose of hypofractionated radiation. In this study we describe the contouring and prescribed dose techniques used in the treatment planning and delivery of radiosurgical treatment to benign neoplasms of the spine using CBCT image guidance. This technique may serve as an important reference for the use of radiosurgery when one believes that it is clinically indicated as a treatment modality for a benign spine tumor that is associated with both a high safety profile and a strong positive clinical outcome.

\section{Disclosure}

Dr. Novotny is a consultant to Elekta AB. The other authors report no conflict of interest concerning the materials or methods used in this study or the findings specified in this paper.

Author contributions to the study and manuscript preparation include the following. Conception and design: Gerszten, Flickinger. Acquisition of data: all authors. Analysis and interpretation of data: Gerszten, Chen, Quader, Xu, Flickinger. Drafting the article: Gerszten, Chen. Critically revising the article: all authors. Reviewed submitted version of manuscript: all authors. Approved the final version of the manuscript on behalf of all authors: Gerszten.

\section{References}

1. Adler JR Jr, Chang SD, Murphy MJ, Doty JR, Geis P, Hancock SL: The Cyberknife: a frameless robotic system for radiosurgery. Stereotact Funct Neurosurg 69:124-128, 1997

2. Asazuma T, Toyama Y, Maruiwa H, Fujimura Y, Hirabayashi K: Surgical strategy for cervical dumbbell tumors based on a three-dimensional classification. Spine (Phila Pa 1976) 29: E10-E14, 2004

3. Benzil DL, Saboori M, Mogilner AY, Rocchio R, Moorthy CR: Safety and efficacy of stereotactic radiosurgery for tumors of the spine. J Neurosurg 101 (Suppl 3):413-418, 2004

4. Bhatnagar AK, Gerszten PC, Ozhasoglu C, Vogel WJ, Kalnicki S, Welch WC, et al: CyberKnife frameless radiosurgery for the treatment of extracranial benign tumors. Technol Cancer Res Treat 4:571-576, 2005

5. Bijl HP, van Luijk P, Coppes RP, Schippers JM, Konings AWT, van Der Kogel AJ: Regional differences in radiosensitivity across the rat cervical spinal cord. Int J Radiat Oncol Biol Phys 61:543-551, 2005

6. Bilsky MH, Angelov L, Rock J, Weaver J, Sheehan J, Rhines L, et al: Spinal radiosurgery: a neurosurgical perspective. J Radiosurg SBRT 1:47-54, 2011

7. Bilsky MH, Laufer I, Fourney DR, Groff M, Schmidt MH, Varga PP, et al: Reliability analysis of the epidural spinal cord compression scale. Clinical article. J Neurosurg Spine 13: $324-328,2010$
8. Bilsky MH, Yamada Y, Yenice KM, Lovelock M, Hunt M, Gutin $\mathrm{PH}$, et al: Intensity-modulated stereotactic radiotherapy of paraspinal tumors: a preliminary report. Neurosurgery 54:823-831, 2004

9. Chang EL, Shiu AS, Lii M-F, Rhines LD, Mendel E, Mahajan A, et al: Phase I clinical evaluation of near-simultaneous computed tomographic image-guided stereotactic body radiotherapy for spinal metastases. Int J Radiat Oncol Biol Phys 59: 1288-1294, 2004

10. Chang SD, Adler JR Jr: Current status and optimal use of radiosurgery. Oncology (Williston Park) 15:209-216, 2001

11. Chang SD, Adler JR Jr: Treatment of cranial base meningiomas with linear accelerator radiosurgery. Neurosurgery 41: 1019-1027, 1997

12. Colombo F, Pozza F, Chierego G, Casentini L, De Luca G, Francescon P: Linear accelerator radiosurgery of cerebral arteriovenous malformations: an update. Neurosurgery 34:1421, 1994

13. Conti P, Pansini G, Mouchaty H, Capuano C, Conti R: Spinal neurinomas: retrospective analysis and long-term outcome of 179 consecutively operated cases and review of the literature. Surg Neurol 61:34-44, 2004

14. Degen JW, Gagnon GJ, Voyadzis JM, McRae DA, Lunsden $\mathrm{M}$, Dieterich S, et al: CyberKnife stereotactic radiosurgical treatment of spinal tumors for pain control and quality of life. J Neurosurg Spine 2:540-549, 2005

15. De Salles AA, Pedroso AG, Medin P, Agazaryan N, Solberg T, Cabatan-Awang C, et al: Spinal lesions treated with Novalis shaped beam intensity-modulated radiosurgery and stereotactic radiotherapy. J Neurosurg 101 (Suppl 3):435-440, 2004

16. Dodd RL, Ryu MR, Kamnerdsupaphon P, Gibbs IC, Chang SD Jr, Adler JR Jr: CyberKnife radiosurgery for benign intradural extramedullary spinal tumors. Neurosurgery 58:674685, 2006

17. Flickinger JC, Pollock BE, Kondziolka D, Lunsford LD: A dose-response analysis of arteriovenous malformation obliteration after radiosurgery. Int J Radiat Oncol Biol Phys 36: 873-879, 1996

18. Gerszten PC, Bilsky MH: Spine radiosurgery. Contemp Neurosurg 28:1-8, 2006

19. Gerszten PC, Monaco EA III, Quader M, Novotny J Jr, Kim JO, Flickinger JC, et al: Setup accuracy of spine radiosurgery using cone beam computed tomography image guidance in patients with spinal implants. Clinical article. J Neurosurg Spine 12:413-420, 2010

20. Gerszten PC, Novotny J Jr, Quader M, Dewald VC, Flickinger JC: Prospective evaluation of a dedicated spine radiosurgery program using the Elekta Synergy S system. Clinical article. J Neurosurg 113 Suppl:236-241, 2010

21. Gerszten PC, Quader M, Novotny J, Flickinger JC: Radiosurgery for benign tumors of the spine: clinical experience and current trends. Technol Cancer Res Treat 11:133-139, 2012

22. Gerszten PC, Welch WC: Combined percutaneous transpedicular tumor debulking and kyphoplasty for pathological compression fractures. Technical note. J Neurosurg Spine 6: 92-95, 2007

23. Gerszten PC, Welch WC: Cyberknife radiosurgery for metastatic spine tumors. Neurosurg Clin N Am 15:491-501, 2004

24. Gezen F, Kahraman S, Canakci Z, Bedük A: Review of 36 cases of spinal cord meningioma. Spine (Phila Pa 1976) 25: 727-731, 2000

25. Gibbs IC, Patil C, Gerszten PC, Adler JR Jr, Burton SA: Delayed radiation-induced myelopathy after spinal radiosurgery. Neurosurgery 64 (2 Suppl):A67-A72, 2009

26. Hamilton AJ, Lulu BA, Fosmire H, Stea B, Cassady JR: Preliminary clinical experience with linear accelerator-based spinal stereotactic radiosurgery. Neurosurgery 36:311-319, 1995

27. Hansen EK, Larson DA, Aubin M, Chen J, Descovich M, Gillis AM, et al: Image-guided radiotherapy using megavolt- 
age cone-beam computed tomography for treatment of paraspinous tumors in the presence of orthopedic hardware. Int $\mathbf{J}$ Radiat Oncol Biol Phys 66:323-326, 2006

28. Hitchcock E, Kitchen G, Dalton E, Pope B: Stereotactic LINAC radiosurgery. Br J Neurosurg 3:305-312, 1989

29. Keilholz L, Seegenschmiedt MH, Sauer R: Radiotherapy for prevention of disease progression in early-stage Dupuytren's contracture: initial and long-term results. Int J Radiat Oncol Biol Phys 36:891-897, 1996

30. Klekamp J, Samii M: Surgery of spinal nerve sheath tumors with special reference to neurofibromatosis. Neurosurgery 42:279-290, 1998

31. Klumpar DI, Murray JC, Anscher M: Keloids treated with excision followed by radiation therapy. J Am Acad Dermatol 31:225-231, 1994

32. Kondziolka D, Lunsford LD, McLaughlin MR, Flickinger JC: Long-term outcomes after radiosurgery for acoustic neuromas. N Engl J Med 339:1426-1433, 1998

33. Kondziolka D, Mathieu D, Martin JJ, Madhok R, Flickinger J, Niranjan A, et al: The long-term perspective on meningioma radiosurgery: experience from over 1,000 tumors. J Neurosurg 106:A740-A741, 2007 (Abstract)

34. Kondziolka D, Nathoo N, Flickinger JC, Niranjan A, Maitz AH, Lunsford LD: Long-term results after radiosurgery for benign intracranial tumors. Neurosurgery 53:815-822, 2003

35. Lee JY, Niranjan A, McInerney J, Kondziolka D, Flickinger JC, Lunsford LD: Stereotactic radiosurgery providing longterm tumor control of cavernous sinus meningiomas. J Neurosurg 97:65-72, 2002

36. Lukacs S, Braun-Falco O, Goldschmidt H: Radiotherapy of benign dermatoses: indications, practice, and results. J Dermatol Surg Oncol 4:620-625, 1978

37. Lunsford LD, Kondziolka D, Flickinger JC, Bissonette DJ, Jungreis CA, Maitz AH, et al: Stereotactic radiosurgery for arteriovenous malformations of the brain. J Neurosurg 75: 512-524, 1991

38. McCormick PC: Surgical management of dumbbell and paraspinal tumors of the thoracic and lumbar spine. Neurosurgery 38:67-75, 1996

39. McCormick PC: Surgical management of dumbbell tumors of the cervical spine. Neurosurgery 38:294-300, 1996

40. Medin PM, Solberg TD, De Salles AA, Cagnon CH, Selch MT, Johnson JP, et al: Investigations of a minimally invasive method for treatment of spinal malignancies with LINAC stereotactic radiation therapy: accuracy and animal studies. Int J Radiat Oncol Biol Phys 52:1111-1122, 2002

41. Milker-Zabel S, Zabel A, Thilmann C, Schlegel W, Wannenmacher M, Debus J: Clinical results of retreatment of vertebral bone metastases by stereotactic conformal radiotherapy and intensity-modulated radiotherapy. Int J Radiat Oncol Biol Phys 55:162-167, 2003

42. Murovic JA, Charles Cho S, Park J: Surgical strategies for managing foraminal nerve sheath tumors: the emerging role of CyberKnife ablation. Eur Spine J 19:242-256, 2010

43. Parsa AT, Lee J, Parney IF, Weinstein P, McCormick PC, Ames C: Spinal cord and intradural-extraparenchymal spinal tumors: current best care practices and strategies. J Neurooncol 69:291-318, 2004

44. Pirzkall A, Lohr F, Rhein B, Höss A, Schlegel W, Wannenmacher $\mathrm{M}$, et al: Conformal radiotherapy of challenging paraspinal tumors using a multiple arc segment technique. Int J Radiat Oncol Biol Phys 48:1197-1204, 2000

45. Prasad D, Steiner M, Steiner L: Gamma surgery for vestibular schwannoma. J Neurosurg 92:745-759, 2000

46. Rock JP, Ryu S, Yin FF: Novalis radiosurgery for metastatic spine tumors. Neurosurg Clin N Am 15:503-509, 2004

47. Ryu S, Fang Yin F, Rock J, Zhu J, Chu A, Kagan E, et al: Image-guided and intensity-modulated radiosurgery for patients with spinal metastasis. Cancer 97:2013-2018, 2003
48. Ryu S, Jin JY, Jin R, Rock J, Ajlouni M, Movsas B, et al: Partial volume tolerance of the spinal cord and complications of single-dose radiosurgery. Cancer 109:628-636, 2007

49. Ryu S, Rock J, Rosenblum M, Kim JH: Patterns of failure after single-dose radiosurgery for spinal metastasis. J Neurosurg 101 (Suppl 3):402-405, 2004

50. Ryu SI, Chang SD, Kim DH, Murphy MJ, Le QT, Martin DP, et al: Image-guided hypo-fractionated stereotactic radiosurgery to spinal lesions. Neurosurgery 49:838-846, 2001

51. Sachdev S, Dodd RL, Chang SD, Soltys SG, Adler JR, Luxton $\mathrm{G}$, et al: Stereotactic radiosurgery yields long-term control for benign intradural, extramedullary spinal tumors. Neurosurgery 69:533-539, 2011

52. Sahgal A, Ma L, Weinberg V, Gibbs IC, Chao S, Chang UK, et al: Reirradiation human spinal cord tolerance for stereotactic body radiotherapy. Int J Radiat Oncol Biol Phys 82:107-116, 2012

53. Saw CB, Ayyangar KM, Zhen W, Thompson RB, Enke CA: Commissioning and quality assurance for MLC-based IMRT. Med Dosim 26:125-133, 2001

54. Seegenschmiedt MH, Martus P, Goldmann AR, Wölfel R, Keilholz L, Sauer R: Preoperative versus postoperative radiotherapy for prevention of heterotopic ossification (HO): first results of a randomized trial in high-risk patients. Int J Radiat Oncol Biol Phys 30:63-73, 1994

55. Seppälä MT, Haltia MJ, Sankila RJ, Jääskeläinen JE, Heiskanen O: Long-term outcome after removal of spinal neurofibroma. J Neurosurg 82:572-577, 1995

56. Seppälä MT, Haltia MJ, Sankila RJ, Jääskeläinen JE, Heiskanen O: Long-term outcome after removal of spinal schwannoma: a clinicopathological study of 187 cases. J Neurosurg 83:621-626, 1995

57. Solan MJ, Kramer S: The role of radiation therapy in the management of intracranial meningiomas. Int J Radiat Oncol Biol Phys 11:675-677, 1985

58. Sperduto PW, Scott C, Andrews D: Stereotactic radiosurgery with whole brain radiation therapy improves survival in patients with brain metastases: report of Radiation Therapy Oncology Group Phase III Study 95-08. Int J Radiat Oncol Biol Phys 54 (2 Suppl 1):3, 2002 (Abstract)

59. Steiner L, Leksell L, Forster DM, Greitz T, Backlund EO: Stereotactic radiosurgery in intracranial arterio-venous malformations. Acta Neurochir (Wien) Suppl 21:195-209, 1974

60. Yamada Y, Bilsky MH, Lovelock DM, Venkatraman ES, Toner S, Johnson J, et al: High-dose, single-fraction imageguided intensity-modulated radiotherapy for metastatic spinal lesions. Int J Radiat Oncol Biol Phys 71:484-490, 2008

61. Yamada Y, Lovelock DM, Bilsky MH: A review of imageguided intensity-modulated radiotherapy for spinal tumors. Neurosurgery 61:226-235, 2007

62. Yin FF, Ryu S, Ajlouni M, Yan H, Jin JY, Lee SW, et al: Image-guided procedures for intensity-modulated spinal radiosurgery. Technical note. J Neurosurg 101 (Suppl 3):419424,2004

Manuscript submitted May 14, 2012.

Accepted August 1, 2012.

Portions of this work were presented at the 16th International Leksell Gamma Knife Society Meeting, Sydney, Australia, March 25-29, 2012.

Please include this information when citing this paper: DOI: 10.3171/2012.8.GKS12981.

Address correspondence to: Peter C. Gerszten, M.D., M.P.H., Department of Neurological Surgery, Presbyterian University Hospital, Suite B-400, 200 Lothrop Street, Pittsburgh, Pennsylvania 15213.email: gersztenpc@upmc.edu. 